\title{
Molecular and Serological Characterization of Cucumber mottle virus, a New Cucurbit-Infecting Tobamo-like Virus
}

\author{
Hiraku Orita, Jun-ichi Sakai, Kenji Kubota, Mitsuru Okuda, Yuko Tanaka, and Kaoru Hanada, National Agri- \\ cultural Research Center for Kyushu Okinawa Region, Suya 2421, Nishigoshi, Kumamoto 861-1192, Japan; \\ Yukihisa Imamura, Miyazaki General Agricultural Research Station, Sadohara, Miyazaki 880-0212, Japan; \\ Masamichi Nishiguchi, Ehime University, Matsuyama 790-8566, Japan; Alexander V. Karasev, Plant, Soil and \\ Entomological Sciences, University of Idaho, Moscow 83844-2339; and Shin-ichi Miyata and Toru Iwanami, Na- \\ tional Institute of Fruit Tree Science, Fujimoto 2-1, Tsukuba, Ibaraki, Japan
}

\begin{abstract}
Orita, H., Sakai, J., Kubota, K., Okuda, M., Tanaka, Y., Hanada, K., Imamura, Y., Nishiguchi, M., Karasev, A. V., Miyata, S., and Iwanami, T. 2007. Molecular and serological characterization of Cucumber mottle virus, a new cucurbit-infecting tobamo-like virus. Plant Dis. 91:1574-1578.
\end{abstract}

A new tobamo-like virus was isolated from a greenhouse-grown cucumber that showed severe mosaic distortion on leaves and fruit, in the southern part of Japan. The virus was tentatively designated Cucumber mottle virus $(\mathrm{CuMoV})$ and further characterized. The size and antigenicity of the coat protein $(\mathrm{CP})$ and the complete sequence of the genome were compared with those of the known cucurbit-infecting tobamoviruses: the $\mathrm{W}$ and $\mathrm{SH}$ strains of Cucumber green mottle mosaic virus (CGMMV), the $\mathrm{C}$ and $\mathrm{Y}$ strains of Kyuri green mottle mosaic virus (KGMMV), Cucumber fruit mottle mosaic virus (CFMMV), and Zucchini green mottle mosaic virus (ZGMMV). The CP of CuMoV migrated more slowly than those of CGMMV-W and -SH and KGMMV-C and $-\mathrm{Y}$ in sodium dodecyl sulfate polyacrylamide gel electrophoresis. In Western blot analysis, the $\mathrm{CP}$ of $\mathrm{CuMoV}$ cross-reacted weakly with antisera against CGMMV-W and did not react with antisera against KGMMV-Y. The overall nucleotide sequence of CuMoV had 62.5 to $63.5 \%$ identity with those of CGMMV-W, -SH, KGMMV-Y, CFMMV, and ZGMMV. The genome organization was characteristic of tobamoviruses, encoding a 131-kb protein, a $188-\mathrm{kb}$ protein, a movement protein (MP), and CP in $5^{\prime}$ to $3^{\prime}$ order. In the phylogenetic analyses of the $\mathrm{CP}, \mathrm{CuMoV}$ was placed in a separate lineage from CGMMV-W, -SH, KGMMV-C, -Y, CFMMV, and ZGMMV. The results indicate that $\mathrm{CuMoV}$ is a distinct tobamovirus species which represents a third sub-subgroup in the cucurbit-infecting tobamoviruses.

Additional keyword: melon

Cucumber green mottle mosaic virus (CGMMV), a member of the genus Tobamovirus, is a serious pathogen for cucurbits. CGMMV was first described by Ainsworth (1), and several strains have been reported from Europe, India, and Japan (11). In Japan, four different strains, CGMMV-W (watermelon strain), -SH (melon strain) $-\mathrm{Y}$ (Yodo strain), and $-\mathrm{C}$

Corresponding author: T. Iwanami

E-mail: tiwsw37@affrc.go.jp

Current addresses for H. Orita, J.-I. Sakai, and K. Hanada: Nagasaki Plant Protection Extension Center, Isahaya, Nagasaki 854-0062, Japan; National Agricultural Research Center for Tohoku Region, Morioka, Iwate, 020-0123, Japan; National Institute of Agrobiological Sciences, Tsukuba, Ibaraki 305-8602, Japan.

* The $e$-Xtra logo stands for "electronic extra" and indicates that Figure 1 appears in color in the online edition.

Accepted for publication 3 July 2007.

doi:10.1094/PDIS-91-12-1574

(C) 2007 The American Phytopathological Society (cucumber strain) have been described $(11,14,21)$. Serological and molecular hybridization analyses and nucleotide sequencing showed that CV3, CV4 (Indian strain C of CGMMV), CGMMV-W, and CGMMV-SH are very closely related, whereas CGMMV-C was quite different $(7,21)$. The novel strain CGMMV-C then was reclassified into Kyuri green mottle mosaic virus (KGMMV) and, thus, redesignated KGMMV-C. Nucleotide sequence homology indicated that CGMMV-Y is closely related to KGMMV-C, and CGMMV-Y was then redesignated KGMMV-Y $(17,19)$. Recently, two new cucurbit-infecting tobamo-like viruses have been reported from Israel and Korea, and they were designated Cucumber fruit mottle virus (CFMMV) and Zucchini green mottle mosaic virus (ZGMMV), respectively $(2,24)$. The serological properties and nucleotide sequences showed that they are distinct from CGMMV and KGMMV, suggesting more diversity of cucurbitinfecting tobamoviruses. Recently, we found a novel tobamo-like virus from cucumber (Cucumis sativus) grown in a greenhouse in Miyazaki Prefecture in the southern part of Japan. Preliminary experiments revealed tobamo-like virus particles, which reacted poorly in doubleantibody sandwich enzyme-linked immunosorbent assay using antisera against CGMMV-W, KGMMV-C, and KGMMV$\mathrm{Y}$ (12). The biological properties of this new virus have been described (12). Briefly, the virus systemically infects several species of cucurbits, causing mild mottling on leaves. The virus induces local lesions in Chenopodium amaranticolor but not in Datura stramonium, similarly to CGMMV-W.

Among the cucurbit-infecting tobamoviruses, the complete sequences of CGMMVSH (22), CGMMV-W (19), KGMMV-Y (19), CFMMV (2), and ZGMMV (24) have been reported. Another isolate of KGMMV-C was characterized and designated as KGMMV-C1 in Korea, and the complete sequence was determined (23). KGMMV-C has been only partially sequenced (19). In this article, we report characterization of the coat protein $(\mathrm{CP})$ and the nucleotide sequence of the virus, which we tentatively designated Cucumber mottle virus (CuMoV). Attempts were made to elucidate relationships with other cucurbit-infecting viruses (CGMMV-W and -SH, KGMMV-C and -Y, CFMMV, and ZGMMV).

\section{MATERIALS AND METHODS}

Virus sources and maintenance. The $\mathrm{CuMoV}$ isolate was obtained originally from cucumber in Miyazaki prefecture, and was maintained by mechanical inoculation of cucumber and melon (Cucumis melo) using $50 \mathrm{mM}$ phosphate buffer $(\mathrm{pH}$ 7.0) containing $0.1 \%$ 2-mercaptoethanol. CGMMV-W and KGMMV-C, which had been isolated by Tochihara and Komuro (21), were obtained from the Genebank of the Ministry of Agriculture, Fishery, and Forestry, Ibaraki 305-8602, Japan (www. gene.affrc.go.jp). CGMMV-SH was obtained from the Shizuoka Agricultural Experiment Station and KGMMV-Y had been deposited in our laboratory by $\mathrm{H}$. Tochihara (retired). Virions were purified from systemically infected melon essentially as described previously (11). All plants were kept in an insect-proof greenhouse. 
Antisera. Antisera against CGMMV-W and KGMMV-Y were provided by $\mathrm{H}$. Tochihara (retired). Antiserum against $\mathrm{Cu}-$ $\mathrm{MoV}$ was raised in a rabbit following a standard immunization procedure (3). All antisera were stored with $0.1 \%$ (wt/vol) sodium azide at $4^{\circ} \mathrm{C}$.

Sodium dodecyl sulfate polyacrylamide gel electrophoresis and Western blotting. Purified virus preparations were analyzed on $12 \%$ polyacrylamide gels containing $0.1 \%$ sodium dodecyl sulfate (SDS) essentially as described by Laemmmli (15). Separated proteins were visualized by staining with Coomassie brilliant blue. For Western blots, proteins were electroblotted to nitrocellulose membranes as described previously (10), and the membranes were placed in plastic trays and blocked with $3 \%(\mathrm{wt} / \mathrm{vol})$ gelatin in Tris-buffered saline (TBS; $20 \mathrm{mM}$ Tris, $500 \mathrm{mM} \mathrm{NaCl}, \mathrm{pH}$ 7.5) for $1 \mathrm{~h}$ with gentle agitation at room temperature. After a brief rinse in TBS with $0.05 \%$ Tween 20 (TTBS), the membranes were incubated with the antiserum at dilutions ranging from $1: 400$ to $1: 3,200$ in phosphate-buffered saline with gentle shaking overnight at room temperature. Membranes were washed in two changes of T-TBS for $5 \mathrm{~min}$ each, then incubated with horseradish peroxidase-conjugated goat anti-rabbit immunoglobulin G (HR-GAR; Bio-Rad, Hercules, CA) at 1:3,000 dilution in T-TBS for 2 $\mathrm{h}$ at room temperature. Final washes included two rinses in T-TBS, followed by one rinse in TBS with gentle shaking, each for $5 \mathrm{~min}$. For colorimetric detection, membranes were incubated in a freshly mixed solution containing hydrogen peroxide and 4-chloro-1-naphthol (HRP color reagent; Bio-Rad; 5).

RNA extraction, reverse-transcription polymerase chain reaction, and sequencing. Viral RNA was extracted from purified virus preparations by a conventional SDS-phenol method and purified by ethanol precipitation $(4,6)$. For initial cloning of the virus genome, a primer (5'TGGGCCCCTACCCGGG-3'), which is complementary to the highly conserved $3^{\prime}$ terminus for all tobamoviruses (25) and contains an SmaI site (underlined), was used for synthesizing the first strand of the cDNA, essentially as described previously (9) using a cDNA synthesis kit (cDNA Synthesis System Plus, RPN 1256Y/Z; Amersham Biosciences, Piscataway, NJ). The second-strand cDNA was synthesized by RNA nicking and priming methods following the procedure provided by the manufacturer of the cDNA synthesis kit. The $3^{\prime}$ overhang on the double-stranded cDNA was removed by T4 DNA polymerase and the blunt-ended cDNA was ligated to the SmaI site of the Bluescript II SK(+) cloning vector (Stratagene, La Jolla, CA) and used to transform Escherichia coli, strain JM 109. Three cDNA clones were sequenced in both directions by dide- oxynucleotide chain termination reaction (18) using the Big Dye terminator cycle sequencing kit (Applied Biosystems, Foster City, CA). After determining the nucleotide sequence of the $3^{\prime}$ region, the upstream regions were amplified by reverse-transcription polymerase chain reaction (RT-PCR) and both strands of the RTPCR products were sequenced, using the specific primers listed in Table 1 . To determine the sequences of the $5^{\prime}$ region, rapid amplification of $5^{\prime}$ cDNA ends (RACE; 8) was performed on purified viral RNA using the two CuMoV-specific primers (Table 1, 5RACE1 and 5RACE2) and the GeneRacer kit (Invitrogen, Carlsbad, CA), following the manufacturers' instructions. For sequencing the $3^{\prime}$ terminal region, 3' RACE (8) was performed using CuMoV-specific primer (Table 1, 3RACE) and oligo(dT) primer after a poly(A) sequence was added to the $3^{\prime}$ terminus of the viral RNA using poly(A) polymerase (Takara, Tokyo). In both $5^{\prime}$ RACE and $3^{\prime}$ RACE, five cDNA clones were sequenced in both directions.

Sequence comparison and phylogenetic analysis. For comparison with $\mathrm{Cu}$ $\mathrm{MoV}$, the sequences of other cucurbitinfecting tobamoviruses were retrieved from the GenBank DNA database. Percent identity was calculated using ALIGN (http://vega.igh.cnrs.fr/bin/align-guess.cgi) using the default settings. Multiple alignment of the sequences was performed using CLUSTAL X (20), and phylogenetic and molecular evolutionary analyses were conducted using the MEGA program, version 3.1 (13) after bootstrapping 1,000 replicates.

\section{RESULTS}

Symptoms and epidemiology. Cucumbers (C. sativus cv. Encore 8) that were infected with $\mathrm{CuMoV}$ first were observed in 18 greenhouses with heating facilities in Miyazaki prefecture in October 1999. Infected plants in the greenhouses developed mosaic symptoms on fruit and leaves. Symptomatic fruit had uneven, distorted shapes and lost commercial value. After mechanical inoculation, $\mathrm{CuMoV}$ induced various symptoms, including mottling and vein clearing. Overall, the symptoms were more severe than those caused by CGMMV-W and -SH, and milder than those of KGMMV-C and -Y on cucumber (Fig. 1). CuMoV induced milder symptoms than CGMMV and KGMMV on melon (data not shown).

Characterization of $\mathbf{C P}$ and serological relationships. The $\mathrm{CP}$ of $\mathrm{CuMoV}$ migrated more slowly than those of CGMMV-W and -SH and KGMMV-C and -Y. It ran faster than the 20.1-kb molecular marker with an apparent molecular weight of 18,000 in SDS-polyacrylamide gel electrophoresis (PAGE) (Fig. 2A).

In Western blot analysis, antiserum against CGMMV-W reacted strongly with the homologous $\mathrm{CP}$ and the $\mathrm{CP}$ of CGMMV-SH, whereas it cross-reacted weakly with $\mathrm{CP}$ of $\mathrm{CuMoV}$ and did not react with CPs of KGMMV-C or KGMMV-

Table 1. Nucleotide sequence and positions of primers used for RT-PCR, rapid amplification of $5^{\prime}$ cDNA ends (5'RACE), 3'RACE, and sequencing

\begin{tabular}{|c|c|c|}
\hline Primer & Sequence $\left(5^{\prime} \rightarrow 3^{\prime}\right)$ & Position $^{a}$ \\
\hline 5END & GCATGTGCTCTGTGTTCA & $221 \leftarrow 238$ \\
\hline $5 \mathrm{R} 1$ & AGAGCACTCGAGCTAGAA & $322 \rightarrow 339$ \\
\hline $5 \mathrm{R} 2$ & AAAGGAGATGTTATCACC & $871 \leftarrow 888$ \\
\hline 1 & TCAATTCATCGCCGATTTTC & $1,118 \rightarrow 1,137$ \\
\hline 5RACE2 & CTGACTAACTGAAACAGA & $1,228 \leftarrow 1,245$ \\
\hline 5RACE1 & GACTCAACCAACATCTGACT & $1,240 \leftarrow 1,259$ \\
\hline 5 & AGTAAGAGTCTGTTCCAG & $1,501 \rightarrow 1,518$ \\
\hline 14 & AGAGATAGTCGCTGAAGT & $1,649 \leftarrow 1,666$ \\
\hline 7 & ATGCGGGAGTCACGGTG & $1,877 \rightarrow 1,893$ \\
\hline 10 & GTTCACCATCATACTGTT & $2,098 \rightarrow 2,115$ \\
\hline 9 & СТTCTTCATTAGGTGCTG & $2,365 \rightarrow 2,383$ \\
\hline 8 & TCATCGGTAAGCACAATT & $2,517 \leftarrow 2,534$ \\
\hline 11 & TAAACCGCTGAGATCGT & $2,731 \rightarrow 2,747$ \\
\hline 6 & ATGGAGAAATTCACGAG & $2,953 \leftarrow 2,969$ \\
\hline 61 & ATCTGTTTGCGATCGCCA & $3,003 \leftarrow 3,020$ \\
\hline 13 & AATAGTAGATAACGTAGA & $3,075 \rightarrow 3,092$ \\
\hline 4 & TGGATTTCATGGACAGTA & $3,321 \leftarrow 3,338$ \\
\hline 15 & GTTTGATCACGAGAAAAT & $3,392 \rightarrow 3,409$ \\
\hline 3 & CGAGGAACTATATCTGACAT & $3,619 \rightarrow 3,638$ \\
\hline 2 & GGTTAATCTACAAGGCTGTA & $3,733 \leftarrow 3,753$ \\
\hline $3 R 2-6$ & TTCAACCACTGATTTCGC & $3,937 \leftarrow 3,954$ \\
\hline $3 R 2-1$ & ATTCCAGGAATGGTATGA & $4,032 \rightarrow 4,049$ \\
\hline $3 R 2-4$ & AGTTTTCAAGGTCTTCTG & $4,316 \leftarrow 4,333$ \\
\hline $3 R 2-3$ & TTATTTGGGAACGTTTAG & $4,436 \rightarrow 4,453$ \\
\hline $3 R 2-2$ & ACCAAAGAATCATCACCA & $4,656 \leftarrow 4,673$ \\
\hline $3 R 2-5$ & GAAAGTATATCATCCATC & $4,778 \rightarrow 4,795$ \\
\hline $\mathrm{R}$ & AGAAGATGGTGATAAGCACT & $4,930 \leftarrow 4,949$ \\
\hline $\mathrm{R} 2$ & TCACTCAGGTACTTGCAAAT & $5,011 \leftarrow 5,030$ \\
\hline 3RACE & CTACGACTGCTGAGTCTT & $6,133 \rightarrow 6,150$ \\
\hline
\end{tabular}

a Arrows $\rightarrow$ and $\leftarrow$ indicate sense and anti-sense primers, respectively. 
Y (Fig. 2B). Antiserum against KGMMV$\mathrm{Y}$ reacted strongly with the homologous $\mathrm{CP}$ as well as that of KGMMV-C, but it did not react with those of CGMMV-W,
CGMMV-SH, and CuMoV (Fig. 2C). Antiserum against $\mathrm{CuMoV}$ gave weak reaction only with the homologous $\mathrm{CP}$ at a 1 to 400 dilution (Fig. 2D). The sensitivity of

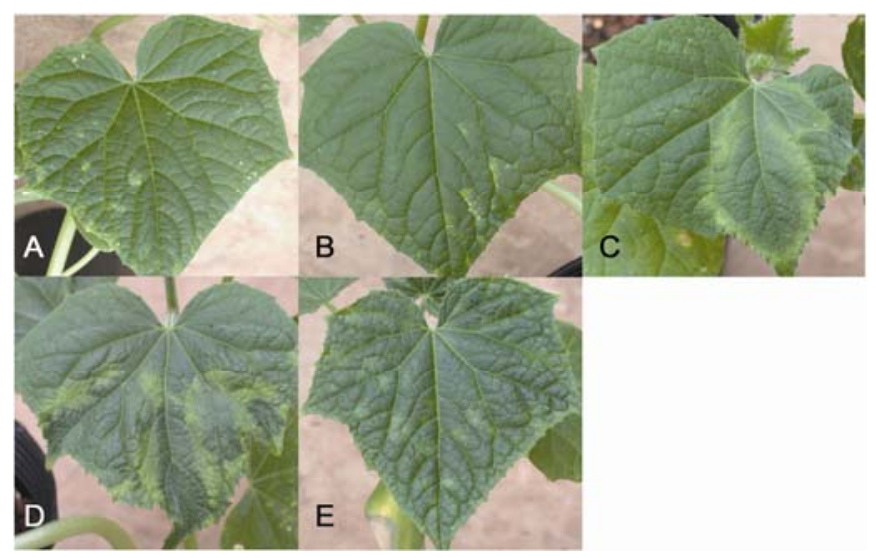

Fig. 1. Symptoms on an upper noninoculated leaf of cucumber inoculated with A, Cucumber green mottle mosaic virus watermelon strain (CGMMV-W); B, CGMMV Shizuoka strain (CGMMV-SH); C, Kyuri green mottle mosaic virus cucumber strain (KGMMV-C), D, KGMMV Yodo strain (KGMMVY); and $\mathbf{E}$, Cucumber mottle virus (CuMoV).

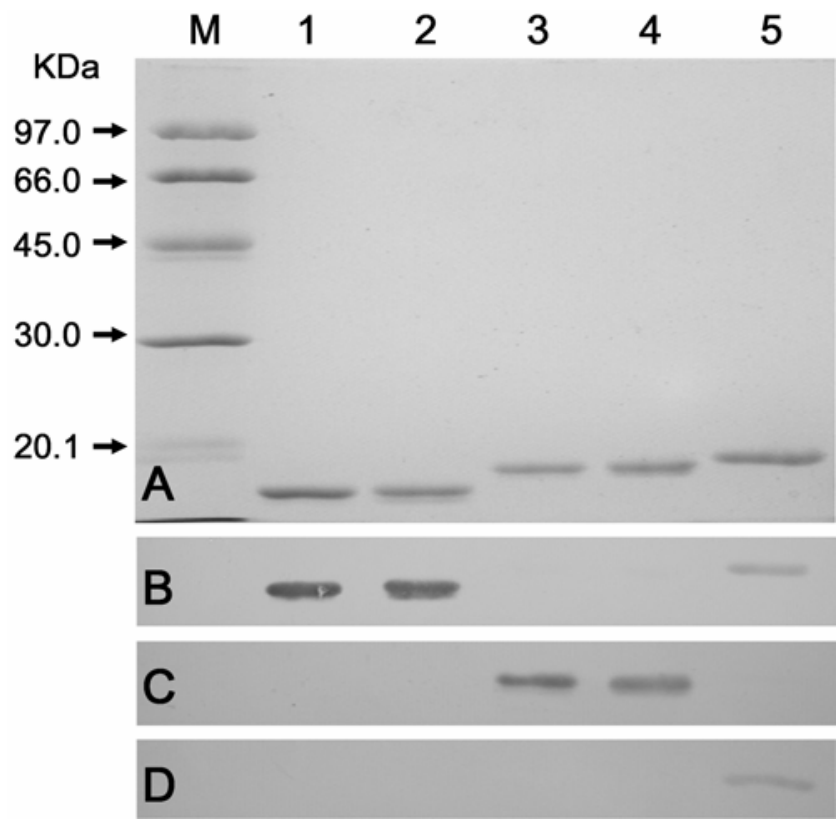

Fig. 2. Sodium dodecyl sulfate polyacrylamide gel electrophoresis (SDS-PAGE) and Western blotting of Cucumber mottle virus (CuMoV), Cucumber green mottle mosaic virus watermelon and Shizuoka strains (CGMMV-W and -SH), and Kyuri green mottle mosaic virus cucumber and Yodo strains (KGMMV-C and -Y). A, Aliquots of purified virion preparations $(1 \mu \mathrm{g}$ each) were analyzed by electrophoresis on a $12 \%$ SDS-polyacrylamide gel and stained with Coomassie brilliant blue; the positions of the molecular weight markers (lane M) are indicated to the left of the gel. Replicate gels were probed with antisera to B, CGMMV-W, C, KGMMV-Y, and D, CuMoV. All antisera were used at 1:400 dilution. Lane 1, CGMMV-W; lane 2, CGMMV-SH; lane 3, KGMMV-C; lane 4, KGMMV-Y; and lane 5, CuMoV.

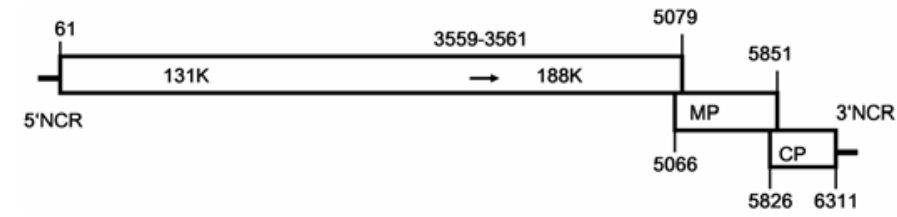

Fig. 3. Proposed genome organization of Cucumber mottle virus $(\mathrm{CuMoV})$. The nucleotide positions of $5^{\prime}$ terminal noncoding region ( $\left.5^{\prime} \mathrm{NCR}\right)$, four encoded proteins (131 and $188 \mathrm{~kb}$, movement protein [MP] and coat protein [CP]), and the $3^{\prime}$ terminal NCR $\left(3^{\prime} \mathrm{NCR}\right)$ are indicated. A readthrough termination codon (UAG) at the nucleotide positions 3,559 to 3,561 is indicated by an arrow.

the homologous reaction was not enhanced when the antiserum was used at lower dilution (data not shown).

Genome organization of CuMoV. The sequence of $\mathrm{CuMoV}$ genomic RNA was determined (GenBank, EMBL, DDBJ accession no. AB261167). It was 6,485 nucleotides in length. Computer analysis revealed four open reading frames on the positive sense strand. The first open reading frame (ORF) was 3,501 nucleotides long and encoded a protein with a calculated molecular weight of 130,913 (131 kb, 1,167 amino acids). This ORF terminated with an amber codon (UAG) at the nucleotide positions 3,559 to 3,561 . The second ORF encoded a read-through protein with a molecular weight of $188,486(188 \mathrm{~kb}$, 1,671 amino acids). The proteins encoded by the third and fourth ORFs had molecular weights of $28,393(28 \mathrm{~kb}, 263$ amino acids) and 17,588 (18 kb, 163 amino acids), respectively. Sequence homology suggested that these proteins are components of the putative RNA polymerase (131 and $188 \mathrm{~kb}$ ), the movement protein (MP; $28 \mathrm{~kb})$, and the $\mathrm{CP}(18 \mathrm{~kb})$. The predicted genome organization (Fig. 3) is characteristic of a Tobamovirus sp. (17).

Sequence comparison among cucurbit-infecting tobamoviruses and phylogenetic analysis. The nucleotide sequence of $\mathrm{CuMoV}$ was about $63 \%$ identical with those of CGMMV-W and -SH, KGMMV-C1, KGMMV-Y, CFMMV, and ZGMMV. Less overall sequence identity $(54.8 \%)$ was observed with noncucurbit-infecting Tomato mosaic virus (ToMV; Table 2). The length of the $5^{\prime}$ noncoding region (NCR) of $\mathrm{CuMoV}$ was 60 nucleotides (nt), which is identical with that of CGMMV-W and SH, longer than those of KGMMV-Y (57 nt) and ZGMMV (58 nt), and shorter than that of CFMMV (62 nt). The nucleotide sequence identities between $\mathrm{CuMoV}$ and other cucurbitinfecting viruses ranged from 46.7 to $66.7 \%$ (Table 2).

The $3^{\prime}$ NCR of CuMoV was $171 \mathrm{nt}$ long. It was longer than those of KGMMV-Y (164 nt) and ZGMMV (163 nt), and shorter than those of CGMMV-W (175 nt), CGMMV-SH (176 nt), and CFMMV (228 nt). Except for the region near the extreme $3^{\prime}$ terminus (nucleotide position 6,428 to 6,455 in $\mathrm{CuMoV}$ ), the sequence of $3^{\prime} \mathrm{NCR}$ was relatively variable among the cucurbitinfecting tobamoviruses. The $3^{\prime} \mathrm{NCR}$ of CuMoV was 52.2 to $70.1 \%$ identical with the corresponding sequences of the other cucurbit-infecting tobamoviruses (Table 2).

The $188-\mathrm{kb}$ protein of $\mathrm{CuMoV}$ was approximately the same size as those of the other known cucurbit-infecting tobamoviruses (CGMMV-W and -SH, 1,652 amino acids [aa]; KGMMV-Y, 1,670 aa; CFMMV, 1,666 aa; and ZGMMV, 1,669 a). The amino acid sequence identities between the putative RNA polymerase of $\mathrm{CuMoV}$ and those of the other cucurbit- 
Table 2. Pairwise sequence comparison of Cucumber mottle virus (CuMoV) and other cucurbit-infecting tobamoviruses ${ }^{\text {a }}$

\begin{tabular}{|c|c|c|c|c|c|c|c|c|c|c|c|}
\hline \multirow[b]{2}{*}{ Virus $^{b}$} & \multirow[b]{2}{*}{ Overall genome } & \multirow[b]{2}{*}{ 5'NCR nt } & \multicolumn{2}{|c|}{$131 \mathrm{~kb}$} & \multicolumn{2}{|c|}{$188 \mathrm{~kb}$} & \multicolumn{2}{|c|}{ MP } & \multicolumn{2}{|c|}{$\mathbf{C P}$} & \multirow[b]{2}{*}{$3^{\prime}$ NCR nt } \\
\hline & & & nt & $\mathbf{a a}$ & nt & $\mathbf{a a}$ & nt & $\mathbf{a a}$ & nt & $\mathbf{a a}$ & \\
\hline CGMMV-W & 63.6 & 66.7 & 60.5 & 58.9 & 63.5 & 63.5 & 64.9 & 60.8 & 59.0 & 53.7 & 70.1 \\
\hline CGMMV-SH & 63.5 & 66.7 & 60.4 & 59.0 & 63.5 & 63.5 & 64.8 & 60.4 & 59.6 & 53.7 & 69.5 \\
\hline KGMMV-C & na & na & na & na & na & na & 61.3 & 56.7 & 59.7 & 43.8 & na \\
\hline KGMMV-C1 & 63.0 & 46.7 & 61.8 & 61.2 & 64.0 & 64.5 & 60.9 & 57.3 & 59.5 & 43.8 & 63.7 \\
\hline KGMMV-Y & 62.8 & 50.8 & 61.6 & 60.2 & 63.7 & 63.7 & 61.1 & 56.7 & 60.1 & 45.1 & 63.6 \\
\hline CFMMV & 62.5 & 55.2 & 61.6 & 59.6 & 63.4 & 62.3 & 63.7 & 59.8 & 58.0 & 41.4 & 52.2 \\
\hline ZGMMV & 63.0 & 46.9 & 61.9 & 61.3 & 64.4 & 64.4 & 60.9 & 57.6 & 62.4 & 46.9 & 61.6 \\
\hline ToMV & 54.8 & 59.2 & 52.7 & 40.0 & 55.0 & 45.4 & 49.4 & 31.0 & 58.8 & 41.4 & 55.2 \\
\hline
\end{tabular}

a Percent identity with $\mathrm{CuMoV}$ of the overall genome, $5^{\prime}$ noncoding region ( $\left.5^{\prime} \mathrm{NCR}\right), 131-\mathrm{kb}$ protein (131 kb), 188-kb protein (188 kb), movement protein (MP), coat protein (CP), and $3^{\prime}$ NCR at nucleotide level (nt) and amino acid level (aa); na = sequence not available.

b Virus acronyms: Cucumber green mottle mosaic virus watermelon strain (CGMMV-W) and Shizuoka strain (CGMMV-SH), Kyuri green mottle mosaic virus cucumber strain (KGMMV-C and -C1) and Yodo strain (KGMMV-Y), Cucumber fruit mottle mosaic virus (CFMMV), Zucchini green mottle mosaic virus (ZGMMV), and Tomato mosaic virus (ToMV). ToMV is included in this comparison as a non-cucurbit-infecting outgroup in the genus Tobamovirus.

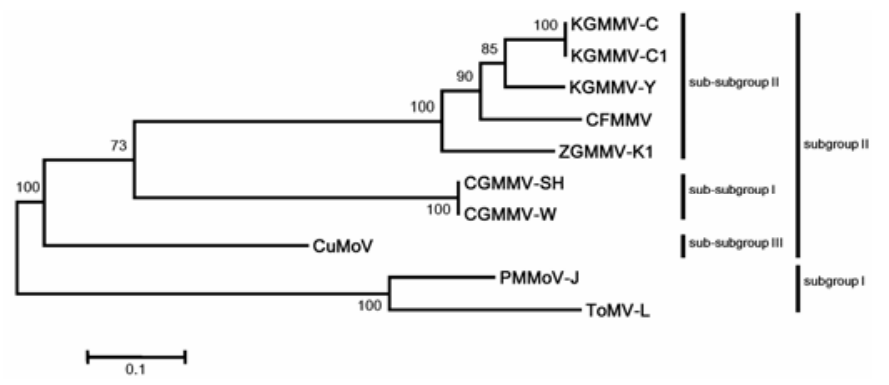

Fig. 4. Phylogenetic tree generated from the alignment of the amino acid sequences of coat protein of Cucumber mottle virus $(\mathrm{CuMoV})$ and other cucurbit-infecting viruses. The numbers at each node indicate bootstrap percentage values obtained from 1,000 replications. The length of the horizontal branches is proportional to the number of amino acid changes. Tomato mosaic virus (ToMV) and Pepper mild mottle virus (PMMoV) were included as outgroups. Abbreviations: Cucumber green mottle mosaic virus watermelon and Shizuoka strain (CGMMV-W and -SH), and Kyuri green mottle mosaic virus cucumber and Yodo stain (KGMMV-C, -C1, and -Y). Cucumber fruit mottle mosaic virus (CFMMV), and Zucchini green mottle mosaic virus (ZGMMV).

infecting tobamoviruses ranged from 62.3 to $64.5 \%$ (Table 2).

The putative MP of CuMoV consisted of 263 aa, which was similar in size to the other tobamoviruses (KGMMV-Y, 262 aa; CFMMV, 258 aa; ZGMMV, 261 aa; CGMMV-W, 264 aa; and CGMMV-SH, 264 aa). The CuMoV MP had 56.7 to $60.8 \%$ amino acid sequence identity with the MP of the other cucurbit-infecting tobamoviruses (Table 2).

The CP of CuMoV had 163 aa residues. The calculated molecular weight $(17,588)$ was close to the estimated value $(18,000)$ by SDS-PAGE. It also was approximately the same size as those of other cucurbitinfecting tobamoviruses: CGMMV-W (162 aa), CGMMV-SH (162 aa), CFMMV (161 aa), ZGMMV (161 aa), and KGMMV-Y (169 aa). The CP of CuMoV had 41.4 to $53.7 \%$ amino acid sequence identity with the other cucurbit-infecting tobamoviruses (Table 2).

There was less sequence identity between the RNA polymerase, MP, CP of $\mathrm{CuMoV}$, and the corresponding proteins of ToMV, a non-cucurbit-infecting tobamovirus (Table 2).

The phylogenetic tree generated from $\mathrm{CP}$ after bootstrapping is presented in Figure $4 . \mathrm{CuMoV}$ was placed into a different lineage from the other cucurbit-infecting tobamoviruses.

\section{DISCUSSION}

In the genus Tobamovirus, virus species are demarcated based on sequence similarity (less than $90 \%$ identity of the genome sequence), host range, and antigenic relationships with other Tobamovirus species (17). CuMoV cannot be distinguished from CGMMV on the basis of host range. However, less than $64 \%$ genome and $\mathrm{CP}$ sequence identity (Table 2) and weak serological cross-reactivity suggest that $\mathrm{CuMoV}$ is a distinct tobamovirus. The comparison of the amino acid sequence of the four encoded proteins and the phylogenetic analysis on $\mathrm{CP}$ gene support the new species status of $\mathrm{CuMoV}$. Thus, we propose Cucumber mottle virus $(\mathrm{CuMoV})$ as a name for this new tobamovirus species infecting cucurbits.

Antignus (2) had proposed that cucurbitinfecting tobamoviruses should be divided into two subgroups; subgroup I includes CGMMV whereas subgroup II consists of KGMMV, CFMMV, and ZGMMV. However, prior to this, it was suggested that the tobamoviruses be divided into three subgroups based on the natural host range and $\mathrm{CP}$ sequence comparison (16). In this classification, all cucurbit-infecting tobamoviruses are in the same subgroup. Therefore, the previously proposed cucurbit-infecting Tobamovirus subgroups are better designated "sub-subgroups." Consequently,
CGMMV is in sub-subgroup I, and KGMMV, CFMMV, and ZGMMV are in sub-subgroup II. CuMoV is distinct from the known cucurbit-infecting tobamoviruses, and might represent a third subsubgroup (sub-subgroup III) of the cucurbit-infecting tobamoviruses.

\section{ACKNOWLEDGMENTS}

We thank S. Adkins for critical reading of the manuscript and M. Hilf for useful suggestions on phylogenetic and molecular evolutionary analysis.

\section{LITERATURE CITED}

1. Ainsworth, G. C. 1935. Mosaic disease of cucumber. Ann. Appl. Biol. 22:55-67.

2. Antignus, Y., Wang, Y., Pearlsman, M. Lachman, O., Lavi, N., and Gal-On, A. 2001. Biological and molecular characterization of a new cucurbit-infecting tobamovirus. Phytopathology 91:565-571.

3. Ball, E. M., Hampton, R. O., De Boer, S. H. Schaad, N. W. 1990. Pages 33-54 in: Serological Methods for Detection and Identification of Viral and Bacterial Plant Pathogens. R. Hampton, E Ball, and S. De Boer, eds. American Phytopathological Society Press, St. Paul, MN.

4. Berger, P. H., and Shiel, P. J. 1998. Pages 151160 in: Plant Virology Protocols: From Virus Isolation to Transgenic Resistance. G. D. Foster and S. C. Taylor, eds. Humana Press, Totowa, NJ

5. Bio-Rad Laboratories. 2007. Protein Blotting A Guide to Transfer and Detection. 3rd ed Bull. 2895. Online at http//www.bio-rad.com.

6. Diener, T. O., and Schneider, I. R. 1968. Virus degradation and nucleic acid release in single phenol systems. Arch. Biochem. Biophys. 124:401-412.

7. Francki, R. I. B., Hu, J., and Palukaitis, P. 1986. Taxonomy of cucurbit-infecting tobamoviruses as determined by serological and molecular hybridization analysis. Intervirology 26:156-163

8. Frohman, M. A., Dush, M. K., and Martin, G. R. 1988. Rapid production of full-length cDNAs from rare transcripts: amplification using a single gene-specific oligonucleotide primer. Proc. Natl. Acad. Sci. USA 85:89889002 .

9. Gubler U., and Hoffman B. J. 1983. A simple and very efficient method for generating cDNA libraries. Gene 25:263-269.

10. Hirano, H., and Watanabe, T. 1990. Microsequencing of proteins electrotransferred onto immobilizing matrices from polyacrylamide gel electrophoresis: application to an insoluble protein. Electrophoresis 11:537-580.

11. Hollings, M., Komuro, Y., and Tochihara, H 1975. Cucumber green mottle mosaic virus. CMI/AAB Descriptions of Plant Viruses No. 154 
12. Imamura, Y., Hanada, K., Ota, T., Nagata, R., and Miura, T. 2000. A new strain of Cucumber green mottle mosaic virus (CGMMV) occurred on cucumber in Miyazaki Prefecture. Kyushu Agric. Res. 62:78.

13. Kumar, S., Tamura, K., and Nei, M. 2004. MEGA3: Integrated software for molecular evolutionary genetics analysis and sequence alignment. Brief. Bioinf. 5:150-163.

14. Komuro, Y., Tochihara, H., Fukatsu, R., Nagai, Y., and Yoneyama, S. 1971. Cucumber green mottle mosaic virus (watermelon strain) in watermelon and its bearing on deterioration of watermelon fruit known as konnyaku disease. Ann. Phytopathol. Soc. Jpn. 37:34-42.

15. Laemmli, U. K. 1970. Cleavage of structural proteins during the assembly of the head of bacteriophage T4. Nature 227:680-685.

16. Lartey, R. T., Voss, T. C., and Melcher U. 1996. Tobamovirus evolution: gene overlaps, recombination, and taxonomic implications. Mol. Biol. Evol. 13:1327-1338.

17. Lewandowski, D. J. 2005. Virus taxonomy: classification and nomenclature of viruses.
Pages 1009-1014 in: 8th Rep. Int. Committee on Taxonomy of Viruses. C. M. Fauquet, M. A Mayo, J. Maniloff, U. Desselberger, and L. A. Ball, eds. Academic Press, San Diego, CA.

18. Sanger, F., Nicklen, S., and Coulson, A. R 1977. DNA sequencing with chain-terminating inhibitors. Proc. Natl. Acad. Sci. USA 74:5463-5467.

19. Tan, S.-H., Nishiguchi, M., Murata, M., and Motoyoshi, F. 2000. The genome structure of Kyuri green mottle mosaic tobamovirus and its comparison with that of Cucumber green mottle mosaic virus. Arch. Virol. 45:1067-1079.

20. Thompson, J. D., Gibson, T. J., Plewniak, F., Jeanmougin, F., and Higgins, D. G. 1997. The CLUSTAL $\mathrm{X}$ windows interface: flexible strategies for multiple sequence alignment aided by quality analysis tools. Nucleic Acids Res. 25:4876-4882.

21. Tochihara, H., and Komuro, Y. 1974. Infectivity test and serological relationships among various isolates of cucumber green mottle virus; some deduction of the invasion route of the virus into Japan. Ann. Phytopa- thol. Soc. Jpn. 40:52-58.

22. Ugaki, M., Tomiyama, M., Kakutani, T., Hidaka, S., Kiguchi, T., Nagata, R., Motoyoshi, F., and Nishiguchi, M. 1991. The complete nucleotide sequence of cucumber green mottle mosaic virus (SH strain) genomic RNA. J. Gen. Virol. 72:1478-1495.

23. Yoon, J. Y., Min, B. E., Choi, S. H., and Ryu, K. H. 2001. Completion of nucleotide sequence and generation of highly infectious transcripts to cucurbits from full-length cDNA clone of Kyuri green mottle mosaic virus. Arch. Virol. 146:2085-2096.

24. Yoon, J. Y., Min, B. E., Choi, J. K., and Ryu, K. H. 2002. Genome structure and production of biologically active in vitro transcripts of cucurbit-infecting Zucchini green mottle mosaic virus. Phytopathology 92:156-163.

25. Zeenko, V. V., Ryabova, L. A., Spirin, A. S., Rothnie, H. M., Hess, D., Browning, K. S., and Hohn, T. 2002. Eukaryotic elongation factor 1A interacts with the upstream pseudoknot domain in the $3^{\prime}$ untranslated region of tobacco mosaic virus RNA. J. Virol. 76:5678-5691. 